\title{
Ultrasonic Investigations on 1-Bromopropane in Chlorobenzene Mixture at 303.15K, 308.15K, 313.15K and 318.15K at $2 \mathrm{MHz}$
}

\author{
Ch. Praveen Babu*, G. Pavan Kumar and K. Samatha \\ Ultrasonic Laboratory, Department of Physics, Andhra University, Visakhapatnam- \\ 530003, India \\ *E-mail: praveenbabu.phd@gmail.com
}

\begin{abstract}
The ultrasonic velocity $(U)$, density $(\rho)$ and viscosity $(\eta)$ have been measured for the binary mixture of 1-Bromopropane with Chlorobenzene at 303.15, 308.15, 313.15 and $318.15 \mathrm{~K}$ at frequency $2 \mathrm{MHz}$. From the experimental data acoustical parameters such as adiabatic compressibility $\left(\beta_{a d}\right)$, intermolecular free length $\left(L_{f}\right)$, acoustic impedance $(Z)$, molar volume $\left(V_{m}\right)$, free volume $\left(V_{f}\right)$, available volume $\left(V_{a}\right)$, relaxation time $(\tau)$, internal pressure $\left(\pi_{i}\right)$ and Gibbs's free energy $\left(\Delta G^{*}\right)$ have been computed. These results are interpreted in terms of molecular interaction between the components of the mixtures.
\end{abstract}

Keywords: Ultrasonic velocity, 1-Bromopropane, Chlorobenzene and molecular interactions

\section{Introduction}

This paper is a continuation of our work related to the study of acoustic, transport and thermodynamic properties of binary mixtures of 1-Bromopropane in Chlorobenzene [1]. The variation of ultrasonic velocity and other ultrasonic parameters of binary liquid mixtures have been studied by many researchers and they have shed light upon structural changes associated with liquid mixtures of weakly or strongly interacting compounds [2-7]. In the present study to explore the nature of interactions occurring between the mixing components, ultrasonic velocity $(U)$, densities $(\rho)$ and viscosity $(\eta)$ of binary mixtures of 1-Bromopropane in Chlorobenzene have been measured over the entire range of composition at 303.15, 308.15, 313.15 and $318.15 \mathrm{~K}$ at $2 \mathrm{MHz}$. By using the above experimental values several acoustic parameters such as adiabatic compressibility $\left(\beta_{a d}\right)$, intermolecular free length $\left(L_{f}\right)$, free volume $\left(V_{f}\right)$, acoustic impedance $(Z)$, molar volume $\left(V_{m}\right)$, available volume $\left(V_{a}\right)$, relaxation time $(\tau)$, internal pressure $\left(\pi_{i}\right)$ and Gibbs's free energy $\left(\Delta G^{*}\right)$ have been reported.

1-Bromopropane composition is disclosed, which stays stable even under the condition that it is repeatedly used at high temperatures over an extended period of time as in vapour degreasing. 1-Bromopropane based fluids have found widespread use in industry for solvent cleaning, i.e., vapor degreasing, cold cleaning and ultrasonic cleaning of complex metal parts, circuit boards, electronic components, implantable prosthetic devices, optical equipment and others [8]. Chlorobenzene is a polar molecule and is important component in synthetic chemistry (produce latex systems), in medicine and biological processes (fungicides, drugs, flavouring extracts, and antiseptics) and is widely used in preparing industrial solvents [9]. The above characteristic physical nature of 1-Bromopropane and Chlorobenzene motivated the authors to study the molecular associations in binary mixtures of 1-Bromopropane and Chlorobenzene over the whole concentration range. 


\section{Experimental Techniques}

Acoustical parameters were calculated using the measure values of velocity, viscosity and density were measured as function of concentration ( 0.0 to 1.0$)$ of binary liquid mixture 1Bromopropane in Chlorobenzene at $2 \mathrm{MHz}$ and at different temperatures $(303.15 \mathrm{~K}, 308.15 \mathrm{~K}$, $313.15 \mathrm{~K}$ and $318.15 \mathrm{~K})$.

The chemicals used were of AR/Merck quality. All were purified by standard procedures discussed in purification of laboratory chemicals before use [10]. Mixtures were prepared by mixing appropriate volumes of liquids in airtight bottles to minimize the evaporation losses and weighed in a single-pan Mettler balance to an accuracy of $\pm 0.001 \mathrm{mg}$. Preferential evaporation losses of solvents from mixtures were kept to a minimum as evidenced by repeated measurement of the physical properties over an interval of 2-3 days, during which no changes in physical properties were observed. The possible error in molefractions is estimated to be around \pm 0.0001 .

The ultrasonic velocities in liquid mixtures have been measured using an ultrasonic interferometer (Model F81) supplied by Mittal Enterprises, New Delhi working at $2 \mathrm{MHz}$ frequency with an accuracy of $\pm 0.1 \mathrm{~m} . \mathrm{sec}^{-1}$. The temperatures were controlled by circulating water around the liquid cell from a thermostatically controlled water bath (accuracy $\pm 0.1^{\circ} \mathrm{C}$ ). The temperature of the cell was measured using a thermocouple (at the crystal) and was found to be accurate to $\pm 0.25^{\circ} \mathrm{C}$. The densities of mixtures were measured using specific gravity bottle and Mettler single pan microbalance (E-METTLER, ZURICH), which allows reading the fifth decimal digit. The purity of the sample was checked by comparing the experimental data of density at four temperatures with the values available in the literature [11]. The viscosity at different temperature was measured using Oswald's Viscometer and stop clock with an accuracy of $\pm 0.0001 \mathrm{Nsm}^{-2}$ and $\pm 0.1 \mathrm{~s}$.

\section{Theory and Calculations:}

Using the measured data, the acoustical parameters have been calculated

1) Adiabatic compressibility $\left(\beta_{a d}\right)$ :

$$
\beta_{a d}=1 / \rho U^{2}
$$

2) Intermolecular free length $\left(L_{f}\right)$ :

$$
L_{f}=K_{T} \sqrt{\boldsymbol{\beta}_{a d}}
$$

3) Free volume $\left(V_{f}\right)$ :

$$
\boldsymbol{V}_{f}=\left(\boldsymbol{M}_{\text {eff }} \boldsymbol{U} / \boldsymbol{k} \eta\right)
$$

4) Acoustic impedance $(Z)$ :

$$
Z=\rho \cdot U
$$

5) Molar Volume ( $\mathrm{Vm})$ :

$$
V_{m}=M / \rho
$$

6) Available volume $\left(V_{a}\right)$ :

$$
\boldsymbol{V}_{a}=(\boldsymbol{M} / \boldsymbol{\rho})\left[\boldsymbol{I}-\left(\boldsymbol{U} / \boldsymbol{U}_{\infty}\right)\right]
$$


7) Relaxation time $(\tau)$ :

$$
\tau=4 / 3 \beta_{a d} \eta
$$

8) Internal pressure $\left(\Pi_{i}\right)$ :

$$
\Pi_{i}=\boldsymbol{b} \boldsymbol{R} \boldsymbol{T}\left(\boldsymbol{k} \boldsymbol{\eta} / \boldsymbol{U}^{2}\right)^{1 / 2}\left(\boldsymbol{\rho}^{2 / 3} / \boldsymbol{M}_{\text {eff }}^{7 / 6}\right)
$$

9) The Gibbs free energy $\left(\Delta G^{*}\right)$ :

$$
\Delta G^{*}=k_{B} T \log \left(k_{B} T \tau / h\right)
$$

where $K_{T}$ is the temperature-dependent constant known as Jacobson's constant. $M_{\text {eff }}$ is the effective molecular weight of the mixture $\left(M_{\text {eff }}=\Sigma m_{i} X_{i}\right.$, where $m_{i}$ and $X_{i}$ are the molecular weight and mole fraction of individual constituents, respectively), $k$ is a temperature independent constant which is equal to $4.281 \times 10^{9}$ for all liquids. $b$ stands for cubic packing, which is assumed to be 2 for all liquids. $T$ is the absolute temperature, $k_{B}$ is Boltzmann's constant, and $h$ is Planck's constant.

\section{Results and Discussions}

The experimental values of ultrasonic velocity, density and viscosity for the binary system 1-Bromopropane in Chlorobenzene with $2 \mathrm{MHz}$ and at different temperatures $(303.15 \mathrm{~K}$, $308.15 \mathrm{~K}, 313.15 \mathrm{~K}$ and $318.15 \mathrm{~K}$ ) are given in the Tables $1,3,5$ and 7 . Adiabatic compressibility $\left(\beta_{a d}\right)$ is a measure of intermolecular association or dissociation or repulsion. It is independent of temperature and pressure. It also determines the orientation of the solvent molecules around the liquid molecules. The structural arrangement of the molecule affects the adiabatic compressibility. From the Tables 1, 3, 5 and 7 it is observed that adiabatic compressibility increases with increase in mole fraction of 1-Bromopropane in the mixture taken up for study which is presented in Figure 4. As adiabatic compressibility is inversely proportional to ultrasonic velocity $(U)$, since ultrasonic velocity decreases with mole fraction, so that adiabatic compressibility increases with mole fraction of 1-Bromopropane shown in Figure 1. From Figure 2 the variation of density $(\rho)$ of 1-Bromopropane + Chlorobenzene system increases with increases in concentration. It is clearly shows the straight line which is proportional to density. Viscosity $(\eta)$ decreases with rise in concentration in system suggesting thereby more association between solute and solvent molecules and given tables and shown in Figure 3.

From Tables 1, 3, 5 and 7 it is also observed that, the values of intermolecular free length $\left(L_{f}\right)$ increases with increase in temperatures and also increases with concentration which is plotted in Figure 5, it clearly reveals that interaction become stronger at higher temperatures. The free length is the distance between the surfaces of the neighbouring molecules. Generally, when the ultrasonic velocity decreases, the value of the free length increases. The increase in intermolecular free length indicates the interaction between the solute and solvent molecules due to which the structural arrangement in the neighbourhood of constituent ions or molecules gets affected considerably.

The variation of molar volume $(\mathrm{Vm})$ with the increase in concentration of 1-Bromopropane are presented in tables 2, 4, 6 and 8 and shown graphically in Figure 6. The increase in concentration molar volume with of 1-Bromopropane predicts the existence of specific interactions among the components in the binary liquid mixture [12]. The decrease in acoustic 
impedance $(Z)$ with increase in concentrations of solutes can be explained in terms of inter and intra molecular interactions between the molecules of liquid systems shown in Figure 7 and Tables 1, 3, 5 and 7. This indicates significant of interaction in liquid system. Acoustic impedance is found to be almost inversely proportional to the adiabatic compressibility.

Free volume $\left(V_{f}\right)$ is defined as the average volume in which the centre of the molecules can move inside the hypothetical cell due to the repulsion of surrounding molecules [13]. Free volume increases with increase in concentration; this may be due to the decrease in vibration of the molecules about their mean position plotted in Figure 8 and in Tables 2, 4, 6 and 8. The compactness and strength of bonding between the components molecules of the liquid mixture are measured directly by the available volume $\left(V_{a}\right)$ [14]. Tables 2, 4, 6 and 8 and Figure 9 shows that the values of available volume $\left(V_{a}\right)$ increase with the increase in concentration of 1-Bromopropane. The increase in available volume is caused due to the net packing of molecules inside the shell which may be due to the complexation between like molecules though hydrogen bonding in the binary mixture. The relaxation time $(\tau)$ decreases with increasing concentration for all the four temperatures presented in Tables 2, 4, 6 and 8 and Figure 10. The dispersion of the ultrasonic velocity in the system should contain information about the characteristic time $\tau$ of the relaxation process that causes dispersion. The relaxation time which is in the order of $10^{-12} \mathrm{sec}$ is due to structural relaxation process [15] and in such a situation it is suggested that the molecules get rearranged due to cooperative process.

Internal Pressure $\left(\Pi_{i}\right)$ is a fundamental property of a liquid, which provides an excellent basis for examining the solution phenomenon and studying various properties of the liquid state. It is a measure of the change in the internal energy of liquid or liquid mixtures, as it undergoes a very small isothermal change. It is a measure of cohesive or binding forces between the solute and solvent molecules. Also it is observed from Tables 2, 4, 6 and 8 and Figure 11 that internal pressure decreases with increase in mole fraction of 1-Bromopropane and also decreases with temperature. The Gibbs free energy $\left(\Delta G^{*}\right)$ increases with the increase in temperature and decrease with increase in concentration of 1-Bromopropane presented in Figure. 12. An increasing value of $\Delta \mathrm{G}^{*}$ suggests that the more distant of unlike molecules is due to hydrogen bonding and longer time for the rearrangement of molecules in the mixture [16].

\section{Table 1. Values of Velocity ( $U$ ), Density $(\rho)$, Viscosity ( $\eta)$, Adiabatic Compressibility $\left(\beta_{a d}\right)$, Intermolecular Free length $\left(L_{f}\right)$ and Acoustic Impedance $(Z)$ at $303.15 \mathrm{~K}$ with Frequency of $2 \mathrm{MHz}$ for Molefraction 1-Bromopropane with Chlorobenzene}

\begin{tabular}{|c|c|c|c|c|c|c|}
\hline $\mathbf{X}_{1}$ & $\begin{array}{c}U \\
\left(\mathrm{~m}_{\mathrm{s}}^{-1}\right) \\
\end{array}$ & $\begin{array}{c}\rho \\
\left(K_{g} \cdot m^{-3}\right) \\
\end{array}$ & $\begin{array}{c}y \\
\left(10^{-3} \text { Ns.m }^{-2}\right) \\
\end{array}$ & $\begin{array}{c}\beta_{a d} \\
\left(10^{-10} \mathrm{~m}^{2} \cdot \mathrm{N}^{-1}\right)\end{array}$ & $\begin{array}{c}L_{f} \\
\left(10^{-10} \mathrm{~m}\right)\end{array}$ & $\begin{array}{c}Z \\
\left(10^{6} \mathrm{Kg} \cdot \mathrm{m}^{2} \cdot \mathrm{s}^{-1}\right)\end{array}$ \\
\hline 0.0000 & 1249.20 & 1095.1 & 0.7151 & 5.8517 & 0.5019 & 1.3680 \\
\hline 0.1836 & 1198.65 & 1137.8 & 0.6747 & 6.1171 & 0.5132 & 1.3638 \\
\hline 0.3599 & 1149.22 & 1180.1 & 0.6346 & 6.4161 & 0.5256 & 1.3562 \\
\hline 0.5290 & 1100.10 & 1222.3 & 0.5950 & 6.7602 & 0.5395 & 1.3447 \\
\hline 0.6921 & 1051.23 & 1261.1 & 0.5547 & 7.1755 & 0.5558 & 1.3257 \\
\hline 0.8488 & 1002.44 & 1299.5 & 0.5145 & 7.6579 & 0.5742 & 1.3027 \\
\hline 1.0000 & 954.47 & 1337.1 & 0.4745 & 8.2094 & 0.5945 & 1.2762 \\
\hline
\end{tabular}


Table 2. Values of Molar Volume $\left(V_{m}\right)$, Free Volume $\left(V_{f}\right)$, Available Volume $\left(V_{a}\right)$, Relaxation Time $(\tau)$, Internal Pressure $\left(\Pi_{i}\right)$ and Gibbs Free Energy $\left(\Delta G^{*}\right)$ at $303.15 \mathrm{~K}$ with Frequency of $2 \mathrm{MHz}$ for Molefraction 1-Bromopropane with Chlorobenzene

\begin{tabular}{|c|c|c|c|c|c|c|}
\hline $\mathbf{X}_{1}$ & $\begin{array}{c}V_{m} \\
\left(10^{-7} \mathrm{~m}^{3} \cdot \mathrm{mol}^{-1}\right)\end{array}$ & $\begin{array}{c}V_{f} \\
\left(10^{-7} \mathrm{~m}^{3} \cdot \mathrm{mol}^{-1}\right)\end{array}$ & $\begin{array}{c}V_{a} \\
\left(10^{-6} \mathrm{~m}^{3} \cdot \mathrm{mol}^{-1}\right)\end{array}$ & $\begin{array}{c}\tau \\
\left(10^{-12} s\right)\end{array}$ & $\begin{array}{c}\pi_{i} \\
\left(10^{6} \text { N.m }{ }^{-2}\right)\end{array}$ & $\begin{array}{c}\Delta G^{*} \\
\left(10^{-20} \mathrm{KJ}^{\prime} \mathrm{mol}^{-1}\right)\end{array}$ \\
\hline 0.0000 & 102.7851 & 3.1128 & 2.2536 & 0.5579 & 338.98 & 0.4659 \\
\hline 0.1836 & 100.6037 & 3.2740 & 2.5236 & 0.5503 & 338.13 & 0.4657 \\
\hline 0.3599 & 98.5527 & 3.4508 & 2.7766 & 0.5429 & 336.84 & 0.4655 \\
\hline 0.5290 & 96.5960 & 3.6413 & 3.0180 & 0.5363 & 335.32 & 0.4653 \\
\hline 0.6921 & 94.9746 & 3.8608 & 3.2574 & 0.5307 & 332.57 & 0.4651 \\
\hline 0.8488 & 93.4321 & 4.1077 & 3.4894 & 0.5253 & 329.34 & 0.4650 \\
\hline 1.0000 & 91.9901 & 4.3937 & 3.7114 & 0.5163 & 325.39 & 0.4648 \\
\hline
\end{tabular}

Table 3. Values of Velocity (U), Density $(\rho)$, Viscosity ( $\eta)$, Adiabatic Compressibility $\left(\beta_{a d}\right)$, Intermolecular Free length $\left(L_{f}\right)$ and Acoustic Impedance $(Z)$ at $308.15 \mathrm{~K}$ with Frequency of $2 \mathrm{MHz}$ for Molefraction 1-Bromopropane with Chlorobenzene

\begin{tabular}{|c|c|c|c|c|c|c|}
\hline $\mathbf{X}_{1}$ & $\begin{array}{c}U \\
\left(\mathrm{~m} . \mathrm{s}^{-1}\right)\end{array}$ & $\begin{array}{c}\rho \\
\left(\mathrm{Kg}^{\left.-\mathbf{m}^{-3}\right)}\right.\end{array}$ & $\begin{array}{c}y \\
\left(10^{-3} \text { Ns.m }^{-2}\right)\end{array}$ & $\begin{array}{c}\beta_{a d} \\
\left(10^{-10} \mathrm{~m}^{2} \cdot \mathrm{N}^{-1}\right)\end{array}$ & $\begin{array}{c}L_{f} \\
\left(10^{-10} \mathrm{~m}\right)\end{array}$ & $\begin{array}{c}Z \\
\left(10^{6} \mathrm{Kg} \cdot \mathrm{m}^{2} \cdot \mathrm{s}^{-1}\right)\end{array}$ \\
\hline 0.0000 & 1229.02 & 1089.9 & 0.6776 & 6.0743 & 0.5163 & 1.3395 \\
\hline 0.1836 & 1179.13 & 1132.1 & 0.6395 & 6.3532 & 0.5281 & 1.3349 \\
\hline 0.3599 & 1130.12 & 1174.1 & 0.6020 & 6.6688 & 0.5410 & 1.3269 \\
\hline 0.5290 & 1081.34 & 1215.7 & 0.5647 & 7.0348 & 0.5557 & 1.3146 \\
\hline 0.6921 & 1032.73 & 1254.1 & 0.5266 & 7.4764 & 0.5728 & 1.2951 \\
\hline 0.8488 & 984.28 & 1291.9 & 0.4888 & 7.9898 & 0.5922 & 1.2716 \\
\hline 1.0000 & 936.31 & 1328.7 & 0.4511 & 8.5849 & 0.6138 & 1.2441 \\
\hline
\end{tabular}

Table 4. Values of Molar Volume $\left(V_{m}\right)$, Free Volume $\left(V_{f}\right)$, Available Volume $\left(V_{a}\right)$, Relaxation Time $(\tau)$, Internal Pressure $\left(\Pi_{i}\right)$ and Gibbs Free Energy $\left(\Delta G^{*}\right)$ at $308.15 \mathrm{~K}$ with Frequency of $2 \mathrm{MHz}$ for Molefraction 1-Bromopropane with Chlorobenzene

\begin{tabular}{|c|c|c|c|c|c|c|}
\hline $\mathbf{X}_{1}$ & $\begin{array}{c}V_{m} \\
\left(10^{-7} \mathrm{~m}^{3} \cdot \mathrm{mol}^{-1}\right)\end{array}$ & $\begin{array}{c}V_{f} \\
\left(10^{-7} \mathrm{~m}^{3} \cdot \mathrm{mol}^{-1}\right)\end{array}$ & $\begin{array}{c}V_{a} \\
\left(10^{-6} \mathrm{~m}^{3} \cdot \mathrm{mol}^{-1}\right)\end{array}$ & $\begin{array}{c}\tau \\
\left(10^{-12} \mathrm{~s}\right)\end{array}$ & $\begin{array}{c}\pi_{i} \\
\left(10^{6} \text { N.m } m^{-2}\right)\end{array}$ & $\begin{array}{c}\Delta G^{*} \\
\left(10^{-20} \text { KJ.mol }{ }^{-1}\right)\end{array}$ \\
\hline 0.0000 & 103.2755 & 3.2933 & 2.3946 & 0.5488 & 337.09 & 0.4737 \\
\hline 0.1836 & 101.1081 & 3.4615 & 2.6596 & 0.5417 & 336.26 & 0.4734 \\
\hline 0.3599 & 99.0531 & 3.6419 & 2.9089 & 0.5353 & 335.17 & 0.4732 \\
\hline 0.5290 & 97.1171 & 3.8378 & 3.1482 & 0.5297 & 333.73 & 0.4730 \\
\hline 0.6921 & 95.5020 & 4.0640 & 3.3860 & 0.5249 & 331.10 & 0.4729 \\
\hline 0.8488 & 93.9801 & 4.3158 & 3.6166 & 0.5207 & 328.02 & 0.4728 \\
\hline 1.0000 & 92.5717 & 4.6053 & 3.8399 & 0.5163 & 324.25 & 0.4726 \\
\hline
\end{tabular}


Table 5. Values of Velocity ( $U$ ), Density $(\rho)$, Viscosity ( $\eta)$, Adiabatic Compressibility $\left(\beta_{a d}\right)$, Intermolecular Free length $\left(L_{f}\right)$ and Acoustic Impedance $(Z)$ at $313.15 \mathrm{~K}$ with Frequency of $2 \mathrm{MHz}$ for Molefraction 1-Bromopropane with Chlorobenzene

\begin{tabular}{|c|c|c|c|c|c|c|}
\hline $\mathbf{X}_{1}$ & $\begin{array}{c}U \\
\left(\mathbf{m} . \mathbf{s}^{-1}\right)\end{array}$ & $\begin{array}{c}\rho \\
\left(\mathrm{Kg}^{-\mathrm{m}^{-3}}\right)\end{array}$ & $\begin{array}{c}y \\
\left(10^{-3} \text { Ns.m }^{-2}\right)\end{array}$ & $\begin{array}{c}\beta_{a d} \\
\left(10^{-10} \mathrm{~m}^{2} \cdot \mathrm{N}^{-1}\right)\end{array}$ & $\begin{array}{c}L_{f} \\
\left(10^{-10} \mathrm{~m}\right)\end{array}$ & $\begin{array}{c}Z \\
\left(10^{6} \mathrm{Kg} \cdot \mathrm{m}^{2} \cdot \mathrm{s}^{-1}\right)\end{array}$ \\
\hline 0.0000 & 1214.29 & 1084.7 & 0.6319 & 6.2524 & 0.5289 & 1.3171 \\
\hline 0.1836 & 1164.57 & 1126.5 & 0.5976 & 6.5454 & 0.5411 & 1.3119 \\
\hline 0.3599 & 1115.49 & 1167.9 & 0.5639 & 6.8812 & 0.5548 & 1.3028 \\
\hline 0.5290 & 1066.49 & 1208.9 & 0.5305 & 7.2727 & 0.5704 & 1.2893 \\
\hline 0.6921 & 1017.72 & 1246.8 & 0.4959 & 7.7437 & 0.5885 & 1.2689 \\
\hline 0.8488 & 969.04 & 1283.9 & 0.4617 & 8.2944 & 0.6091 & 1.2441 \\
\hline 1.0000 & 920.46 & 1319.9 & 0.4275 & 8.9423 & 0.6325 & 1.2159 \\
\hline
\end{tabular}

Table 6. Values of Molar Volume $\left(V_{m}\right)$, Free Volume $\left(V_{f}\right)$, Available Volume $\left(V_{a}\right)$, Relaxation Time $(\tau)$, Internal Pressure $\left(\Pi_{i}\right)$ and Gibbs Free Energy $\left(\Delta G^{*}\right)$ at 313.15K with Frequency of $2 \mathrm{MHz}$ for Molefraction 1-Bromopropane with Chlorobenzene

\begin{tabular}{|c|c|c|c|c|c|c|}
\hline $\mathbf{X}_{1}$ & $\begin{array}{c}V_{m} \\
\left(10^{-7} \mathrm{~m}^{3} \cdot \mathrm{mol}^{-1}\right) \\
\end{array}$ & $\begin{array}{c}V_{f} \\
\left(10^{-7} \mathrm{~m}^{3} \cdot \mathrm{mol}^{-1}\right)\end{array}$ & $\begin{array}{c}V_{a} \\
\left(10^{-6} \mathrm{~m}^{3} \cdot \mathrm{mol}^{-1}\right) \\
\end{array}$ & $\begin{array}{c}\tau \\
\left(10^{-12} s\right) \\
\end{array}$ & $\begin{array}{c}\pi_{i} \\
\left(10^{6} \mathrm{~N} \cdot \mathrm{m}^{-2}\right)\end{array}$ & $\begin{array}{c}\Delta G^{*} \\
\left(10^{-20} \mathrm{KJ}_{\mathrm{m}} \mathrm{mol}^{-1}\right)\end{array}$ \\
\hline 0.0000 & 103.7706 & 3.5914 & 2.5016 & 0.5393 & 331.74 & 0.4809 \\
\hline 0.1836 & 101.6081 & 3.7610 & 2.7652 & 0.5318 & 331.30 & 0.4807 \\
\hline 0.3599 & 99.5752 & 3.9392 & 3.0153 & 0.5257 & 330.65 & 0.4806 \\
\hline 0.5290 & 97.6594 & 4.1280 & 3.2564 & 0.5209 & 329.77 & 0.4805 \\
\hline 0.6921 & 96.0578 & 4.3504 & 3.4958 & 0.5168 & 327.65 & 0.4804 \\
\hline 0.8488 & 94.5638 & 4.5924 & 3.7291 & 0.5133 & 325.17 & 0.4803 \\
\hline 1.0000 & 93.1889 & 4.8657 & 3.9578 & 0.5101 & 322.10 & 0.4801 \\
\hline
\end{tabular}

Table 7. Values of Velocity ( $U$ ), Density $(\rho)$, Viscosity ( $\eta)$, Adiabatic Compressibility $\left(\beta_{a d}\right)$, Intermolecular Free length $\left(L_{f}\right)$ and Acoustic Impedance $(Z)$ at $318.15 \mathrm{~K}$ with Frequency of $2 \mathrm{MHz}$ for Molefraction 1-Bromopropane with Chlorobenzene

\begin{tabular}{|c|c|c|c|c|c|c|}
\hline$X_{1}$ & $\begin{array}{c}U \\
\left(\mathbf{m} \cdot \mathrm{s}^{-1}\right)\end{array}$ & $\begin{array}{c}\rho \\
\left(K^{\prime} \cdot m^{-3}\right) \\
\end{array}$ & $\begin{array}{c}y \\
\left(10^{-3} \text { Ns.m }{ }^{-2}\right) \\
\end{array}$ & $\begin{array}{c}\beta_{a d} \\
\left(10^{-10} \mathrm{~m}^{2} \cdot \mathrm{N}^{-1}\right)\end{array}$ & $\begin{array}{c}L_{f} \\
\left(10^{-10} \mathrm{~m}\right)\end{array}$ & $\begin{array}{c}Z \\
\left(10^{6} \mathrm{Kg} \cdot \mathrm{m}^{2} \cdot \mathrm{s}^{-1}\right)\end{array}$ \\
\hline 0.0000 & 1198.09 & 1079.5 & 0.5904 & 6.4535 & 0.5424 & 1.2933 \\
\hline 0.1836 & 1149.06 & 1120.9 & 0.5601 & 6.7569 & 0.5550 & 1.2880 \\
\hline 0.3599 & 1100.33 & 1161.8 & 0.5307 & 7.1092 & 0.5693 & 1.2784 \\
\hline 0.5290 & 1051.44 & 1202.1 & 0.5012 & 7.5247 & 0.5857 & 1.2639 \\
\hline 0.6921 & 1002.67 & 1239.6 & 0.4705 & 8.0242 & 0.6048 & 1.2429 \\
\hline 0.8488 & 954.15 & 1275.9 & 0.4399 & 8.6089 & 0.6264 & 1.2174 \\
\hline 1.0000 & 905.29 & 1311.1 & 0.4095 & 9.3066 & 0.6513 & 1.1869 \\
\hline
\end{tabular}


Table 8. Values of Molar Volume $\left(V_{m}\right)$, Free Volume $\left(V_{f}\right)$, Available Volume $\left(V_{a}\right)$, Relaxation Time $(\tau)$, Internal Pressure $\left(\Pi_{i}\right)$ and Gibbs Free Energy $(\Delta G)$ at $318.15 \mathrm{~K}$ with Frequency of $2 \mathrm{MHz}$ for Molefraction 1-Bromopropane with

\section{Chlorobenzene}

\begin{tabular}{|c|c|c|c|c|c|c|}
\hline $\mathbf{X}_{1}$ & $\begin{array}{c}V_{m} \\
\left(10^{-7} \mathrm{~m}^{3} \cdot \mathrm{mol}^{-1}\right)\end{array}$ & $\begin{array}{c}V_{f} \\
\left(10^{-7} \mathrm{~m}^{3} \cdot \mathrm{mol}^{-1}\right)\end{array}$ & $\begin{array}{c}V_{a} \\
\left(10^{-6} \mathrm{~m}^{3} \cdot \mathrm{mol}^{-1}\right)\end{array}$ & $\begin{array}{c}\tau \\
\left(10^{-12} s\right)\end{array}$ & $\begin{array}{c}\pi_{i} \\
\left(10^{6} \mathbf{N} \cdot \mathrm{m}^{-2}\right)\end{array}$ & $\begin{array}{c}\Delta G^{*} \\
\left(10^{-20} \text { KJ.mol }{ }^{-1}\right)\end{array}$ \\
\hline 0.0000 & 104.2705 & 3.8974 & 2.6192 & 0.5298 & 327.00 & 0.4888 \\
\hline 0.1836 & 102.1132 & 4.0623 & 2.8779 & 0.5229 & 326.97 & 0.4886 \\
\hline 0.3599 & 100.0941 & 4.2267 & 3.1259 & 0.5177 & 326.93 & 0.4884 \\
\hline 0.5290 & 98.2077 & 4.4002 & 3.3670 & 0.5137 & 326.76 & 0.4883 \\
\hline 0.6921 & 96.6124 & 4.6031 & 3.6068 & 0.5102 & 325.42 & 0.4882 \\
\hline 0.8488 & 95.1547 & 4.8244 & 3.8410 & 0.5080 & 323.63 & 0.4881 \\
\hline 1.0000 & 93.8144 & 5.0622 & 4.0734 & 0.5058 & 321.51 & 0.4880 \\
\hline
\end{tabular}

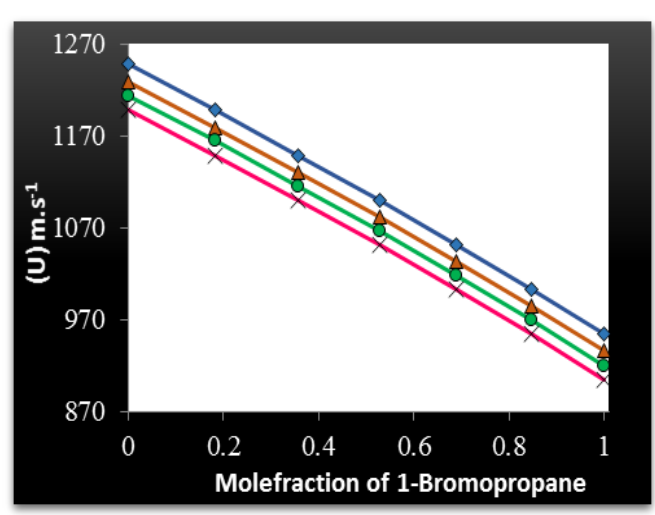

Figure 1. Variation of Velocity with Molefraction of 1-Bromopropane

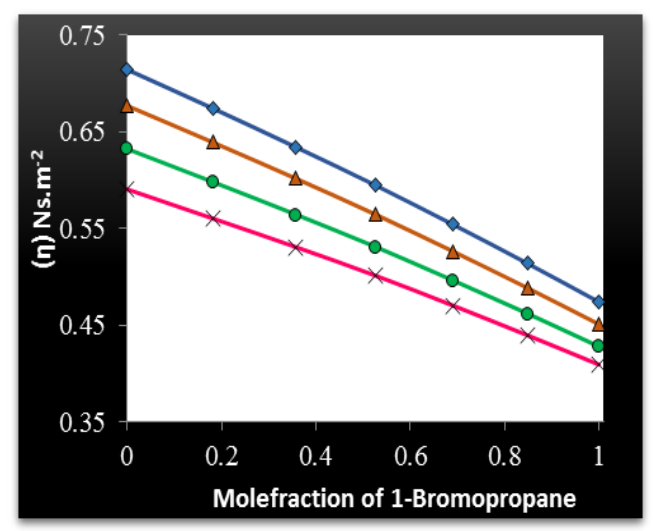

Figure 3. Variation of Viscosity with Molefraction of 1-Bromopropane

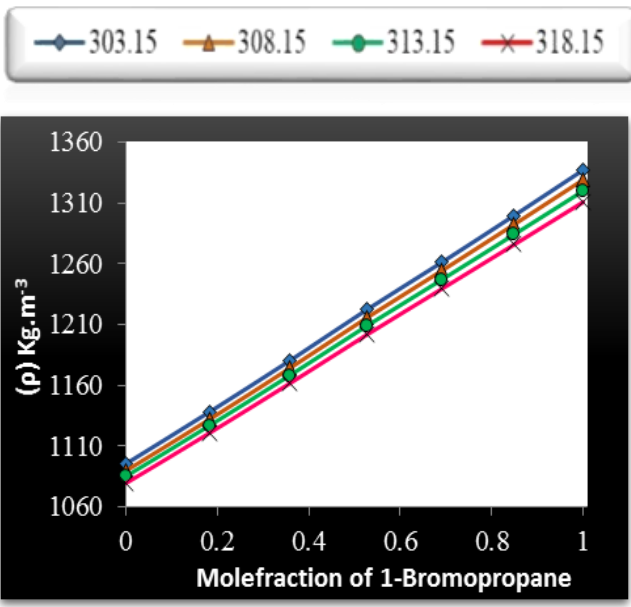

Figure 2. Variation of Density with Molefraction of 1-Bromopropane

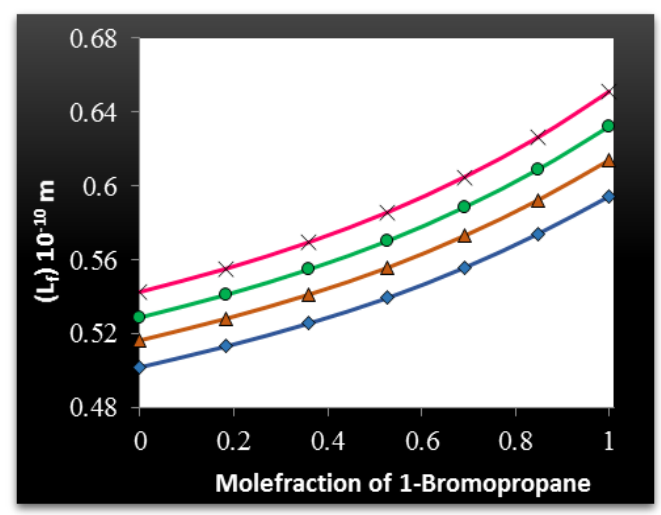

Figure 4. Variation of Adiabatic Compressibility with Molefraction of 1-Bromopropane 


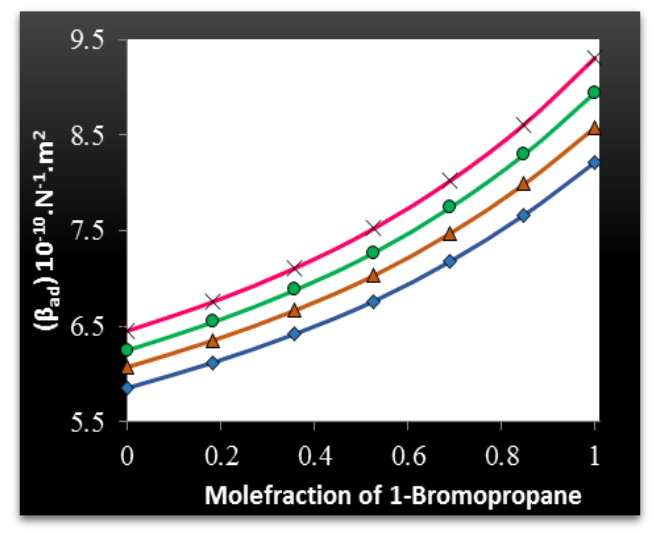

Figure 5. Variation of Intermolecular Free Length with Molefraction of 1Bromopropane

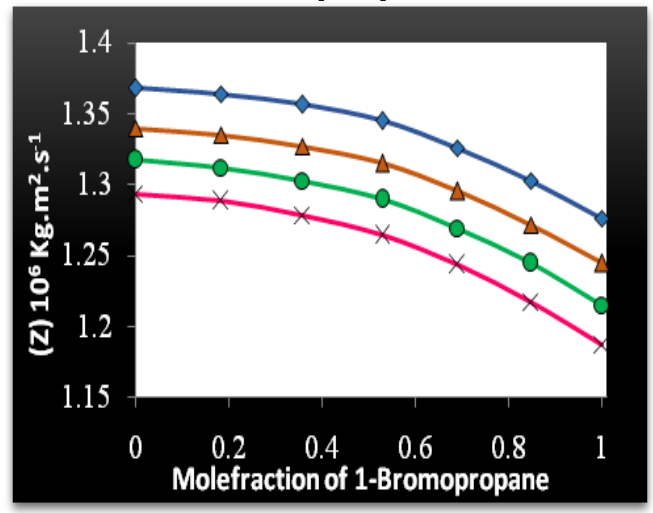

Figure 6. Variation of Molar Volume with Molefraction of 1Bromopropane

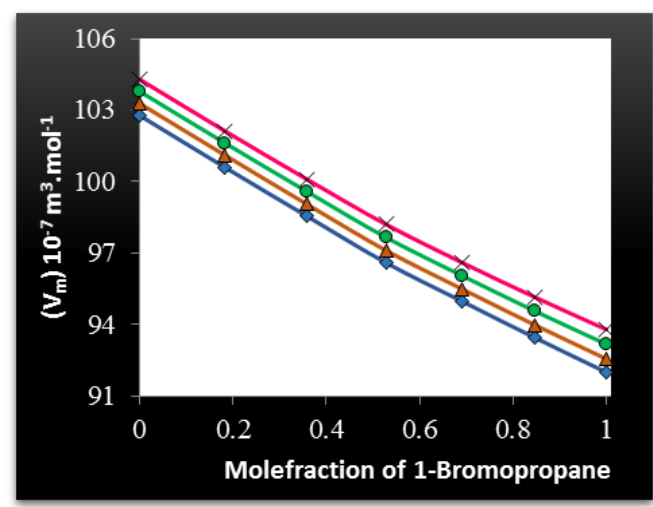

Figure 7. Variation of Acoustic Impedance with Molefraction of 1Bromopropane

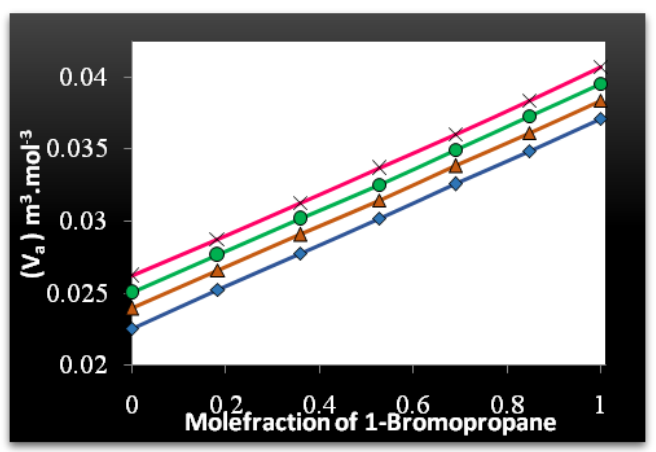

Figure 9. Variation of Available Volume with Molefraction of 1Bromopropane

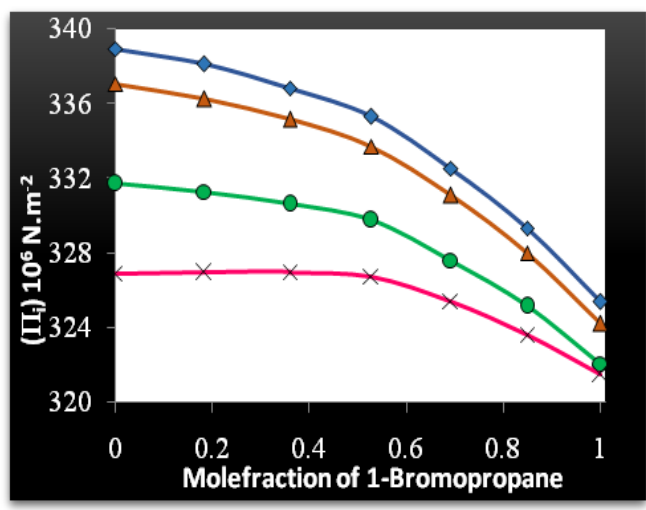

Figure 11. Variation of Internal Pressure with Molefraction of 1Bromopropane

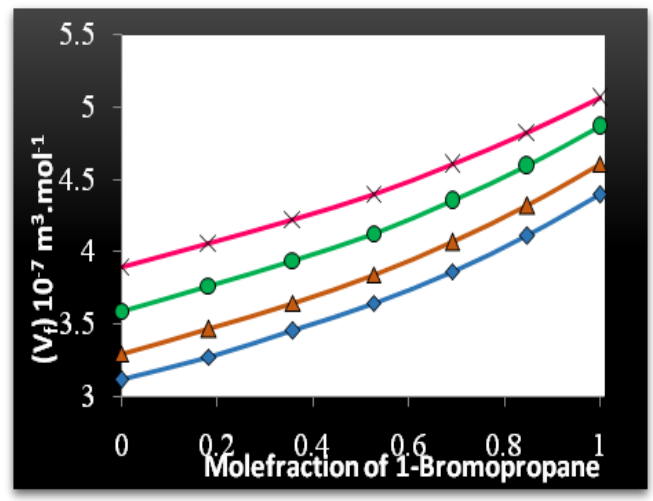

Figure 8. Variation of Free Volume with Molefraction of 1Bromopropane 


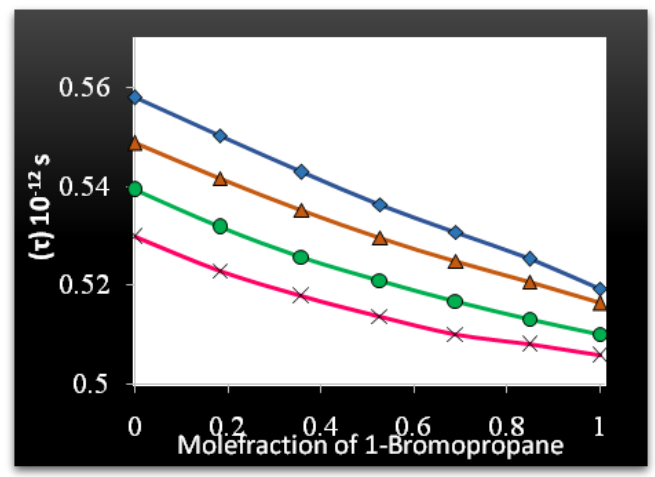

Figure 10. Variation of Relaxation Time with Molefraction of 1Bromopropane

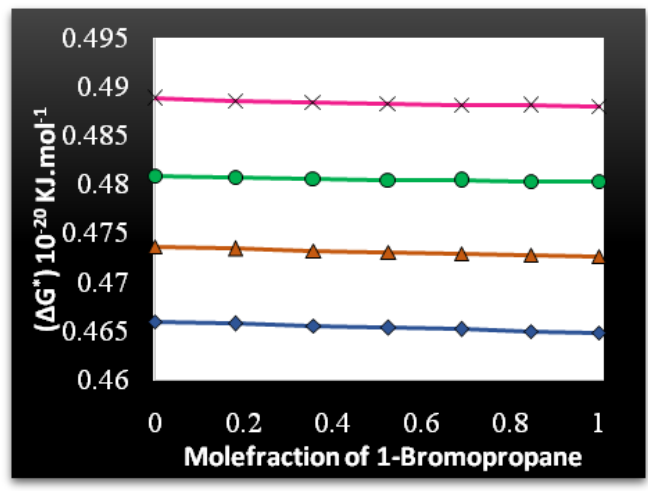

Figure 12. Variation of Gibbs free energy with Molefraction of 1Bromopropane

\section{Conclusion}

From the observed experimental values of ultrasonic velocity, density, viscosity and related acoustical parameters values for the binary liquid mixtures of 1-Bromopropane and Chlorobenzene system at temperatures $303.15 \mathrm{~K}, 308.15 \mathrm{~K}, 313.15 \mathrm{~K}$ and $318.15 \mathrm{~K}$, it is clear that there exists a strong intermolecular association between the component molecules of the liquid mixtures.

\section{Acknowledgement}

One of authors Ch. Praveen Babu highly thankful to the University Grants Commission, India, for funding the current research work under UGC Scholarship Assistance Program (SAP) in the Department of Physics, Andhra University.

\section{References}

[1] Ch. Praveen. Babu, G. Pavan Kumar, B. Nagarjun and K. Samatha, Int. Let. Chem. Phy and Astro., vol. 11, no. 1, (2014), pp. 9.

[2] H. N. V. Temperley, J. S. Rawlinson and G. S. R. Brooke, Phys. of simple liquids (John Wiley, New York), (1968).

[3] K. Samatha, K. S. Rao and J. S. Murthy, J. Pure Appl. Ultrasonics, vol. 20, no. 1, (1998).

[4] J. V. Sastry, K. Samatha and A. V. Sarma, J. Pure Appl. Ultrasonics, vol. 25, no. 109, (2003).

[5] A. V. Sarma, K. Samatha and J. S. Murthy, J. Acoust. Soc. Ind., vol. 31, no. 334, (2003).

[6] G. Pavan. Kumar, Ch. Praveen. Babu, K. Samatha, A. N. Jyosthna and K. Showrilu, Int. Let. Chem. Phy and Astro., vol. 10, no. 25, (2014).

[7] G. Pavan. Kumar, Ch. Preveen. Babu, K. Samatha, A. N. Jyosthna and K. Showrilu, Int. J. Research in Pure and Appl. Phy., vol. 4, no. 1, (2014), pp. 1.

[8] S. S. Yadava and A. Yadav, Ind. J. Pure and Appl. Phys., vol. 42, no. 338, (2004).

[9] S. Kumar, D. R. Sharma, N. Thakur, N. S. Negi and V. S. Rangra, J. Mol. Liq., vol. 130, no. 70, (2007).

[10] D. D. Perrin and W. L. F. Armarego, Pergamon Press, Oxford, vol. 399, (1988).

[11] "Hand Book of Chemistry and Physics (CRC Press)", 60th ed. CRC Press Inc. Ohio, (1979-80).

[12] J. N. Nayak, M. I. Aralaguppi and T. M. Aminabhavi, J. Chem. Eng. Data, vol. 48, no. 628, (2003).

[13] M. K. Praharaj, P. R. Mishra, S. Mishra and A. Satapathy, "Archives of Physics Research", vol. 3, no. 3, 192, (2012).

[14] L. E. Kinsler and A. R. Rray, "Fundamentals of Acoustics" (Wiley Eastern, New Delhi), (1989).

[15] S. Kalyanansundaram, S. Natarajan and B. M. Stephen, Acta Acoustica, vol. 83, no. 74, (1997).

[16] C. S. Priya, S. Nithya, G. Velraj and A. N. Kanappan, Int. J. Advanced Sci. and Technology, vol. 18, no. 59, (2010). 


\section{Authors}

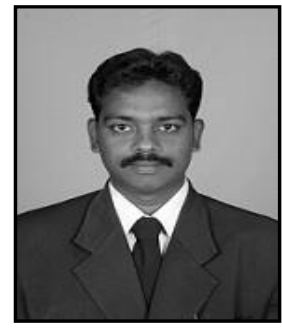

Ch. Praveen Babu, he has been currently involved in doing his Ph.D in Ultrasonics under the guidance of Prof. K. Samatha at Andhra University, Visakhapatnam, India. He has completed his M.Phil in the field of Ultrasonics at Andhra University, India, under the guidance of Prof. K. Samatha, M.Sc (Electronics) in Acharya Nagarjuna University, India, B.Sc (Electronics) in Hindu College, Machilipatnam and Andhra Pradesh, India.

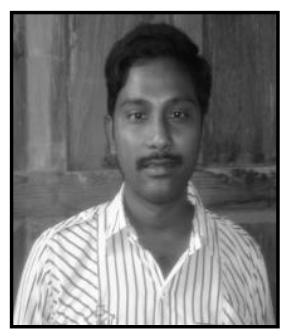

G. Pavan Kumar, he has been submitted his $\mathrm{Ph} . \mathrm{D}$ in Ultrasonics under the guidance of Prof. K. Samatha at Andhra University, Visakhapatnam, India. He has completed his M.Sc (Physics) in Acharya Nagarjuna University, India, B.Sc (Physics) in P. B. Siddhartha College of Arts \& Science, Vijayawada and Andhra Pradesh, India.

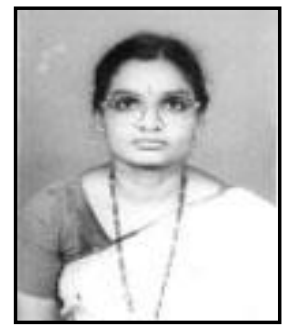

K. Samatha, she is working as a Professor in the Physics department, Andhra University, Visakhapatnam, India. She has completed her Ph.D from Andhra University, Visakhapatnam, India. She has completed her M.Sc (Physics) (Solid State Physics) in Andhra University, Visakhapatnam, India. She is currently working in the fields of Solid State Physics and Ultrasonics. 